\title{
Influence of Laser Energy on the Structural and Optical Properties of (CdO):(CoO) Thin Films Produced by Laser-
}

\section{Induced Plasma (LIP)}

\author{
Kadhim A. Aadim, Maryam M. Shehab \\ Department of Physics, College of Science, University of Baghdad, Baghdad, Iraq \\ E-mail: kadhim_adem@scbaghdad.edu.iq \\ Corresponding author: maryammajidshehab@gmail.com
}

\begin{abstract}
In this work, The influence of laser energy on structural and optical properties of $(\mathrm{CdO}):(\mathrm{CoO})$ thin films deposited on glass slides by the pulse laser deposition technique (PLD) was studied using The laser used was Nd:YAG laser with $(\lambda=1064 \mathrm{~nm})$ and duration $(9 \mathrm{~ns})$ with different laser energies $(200-500 \mathrm{~mJ})$ for $(1: 1)$. X-ray diffraction patterns showed that all the films had a polycrystalline with cubic crystal structure. As for the topography of the films surface, it was measured using AFM, where the results showed that the grain size and the average roughness increase with increasing laser energy. The optical properties of all films were studied and the results showed that the absorption coefficient within the wavelength range (280-1100 $\mathrm{nm}$ ) increases with increasing laser energy, It was shown that the optical power gap value for direct transitions decreased by increasing laser energy within the range (4.25-3.55) eV.
\end{abstract}

Key words

Laser Induced Plasma (LIP), $(\mathrm{CdO}):(\mathrm{CoO})$ thin films, structural properties, optical properties.

\section{Article info.}

Received: Jan. 2021

Accepted: Mar. 2021

Published: Jun. 2021

\section{تأثير طاقة الليزر على الخصائص التركيبية والبصرية لاغثبة CdO:CoO المنتجة بالبلازما

$$
\begin{aligned}
& \text { المحتثة بالليزر } \\
& \text { كاظم عبد الواحد عادم، مريم ماجد شهاب } \\
& \text { قسم الفيزياء، كلية العلوم، جامعة بغداد، بغداد، العراق }
\end{aligned}
$$

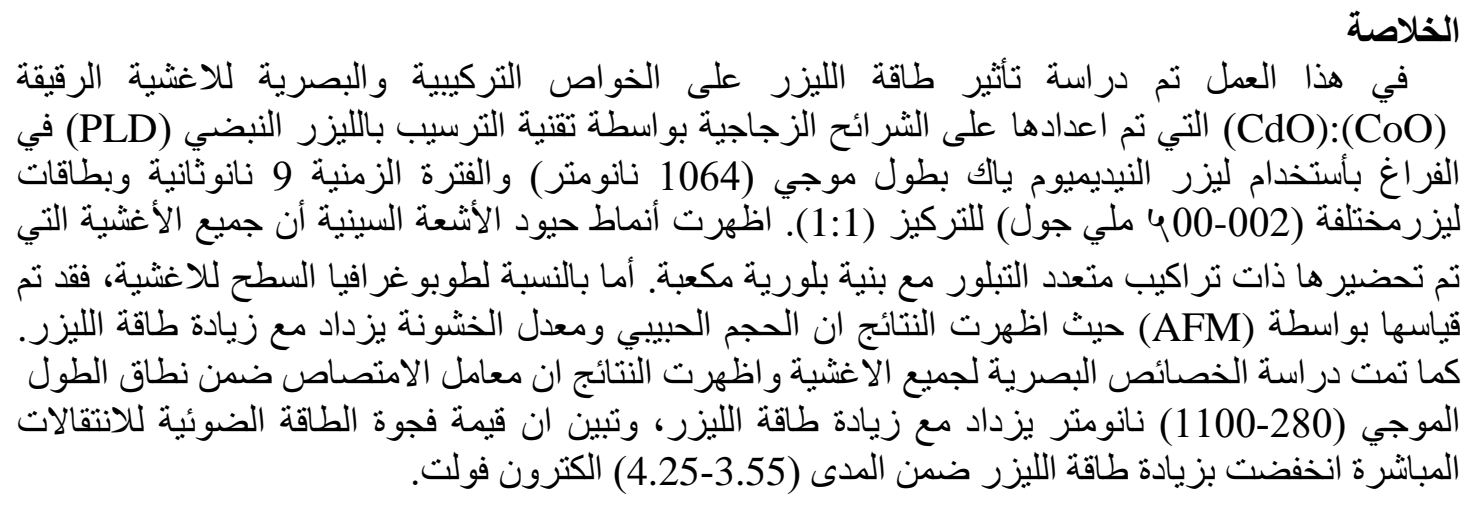

Iraqi Journal of Physics by IJP is licensed under a Creative Commons Attribution 4.0 International License.

Based on a work at http://ijp.uobaghdad.edu.iq/index.php/physics. @) (1) 


\section{Introduction}

Cadmium oxide $(\mathrm{CdO})$ is an $\mathrm{N}$ semiconductor of interesting properties, such as low electrical conductivity [1]. It has a molecular weight of $(128.4 \mathrm{~g} / \mathrm{mol})$, density $(8.15 \mathrm{~g} / \mathrm{cm}-3)$, as well as having a forbidden energy gap of ranging between (2.162.6) $\mathrm{eV}$. CdO can be used in many practical applications and different technological industries as a translucent conductive material and a thin film. [2]. Cobalt oxide $(\mathrm{CoO})$ is an important material that is used in different fields, such as heterogeneous catalysts. [3], energy storage [4], and in electrochemical devices, etc. Nanostructures of $(\mathrm{CoO})$ have been shown to show capacitance in negative potential and may also serve as suitable positive electrodes in devices [5]. The electronic and optical characteristics of nanoparticles for $(\mathrm{CoO})$ are powerfully dependent on their size and form [6]. CoO has a molecular weight of $(74.933 \mathrm{gm} / \mathrm{mole})$, density $\left(6.11 \mathrm{gm} / \mathrm{cm}^{-3}\right)$, and a forbidden energy gap ranging between $(2.2-2.4) \mathrm{eV}$ [7].

The deposition method by pulsed laser ablation technique is one of the best and low coast techniques for the deposition of semiconductors, metals, and their oxides under different technological conditions [8]. Pulsed laser deposition (PLD) preferably uses high-energy laser pulses with an energy density of more than $10^{8}\left(\mathrm{~W} / \mathrm{cm}^{2}\right)$ to deposit a thin layer of a single target. There are several techniques that can be used for the purpose of deposition, including chemical bath deposition (CBD), magnetron sputtering (MS), chemical vapor deposition (CVD), and pulsed laser deposition (PLD) [9-11].

This research aims to prepare $(\mathrm{CdO}: \mathrm{CoO})$ thin films using PLD method on glass substrates and study the effect of changing the energy of the laser pulse on the structural and optical properties

\section{Experimental work}

In this work, PLD was chosen for the deposition (CdO:CoO) films. Thin film growth is achieved by directing the laser onto the target (pellet), which leads to the evaporation of the material and its growth on the substrate. The laser used for the growth method of films is Nd: YAG laser with a wavelength of $1064 \mathrm{~nm}$. The evaporation process depends on the laser parameters such as laser energy and pulses duration [12]. X-ray diffraction (XRD) was used to calculate the crystalline structure and grain size of the (CdO:CoO) films prepared by PLD techniques. The grain size (D) was calculated by using Scherrer's equation [13].

$$
D=\frac{K \cdot \lambda}{\beta \cos \theta}
$$

where $\mathrm{k}$ is a constant taken to be $0.94, \lambda$ is the wavelength of $\mathrm{X}$-ray $(1.54 \AA), \beta$ is full width at half maximum (FWHM), and $\theta$ is Bragg's angle [14].

The optical properties were studied using a double beam UV-Vis spectrophotometer (MetertechSP8001, Taiwan). The optical band gap was estimated graphically by applying Tauc's relation for direct transition [15]:

$$
\alpha \boldsymbol{h v}=\boldsymbol{B}\left(\boldsymbol{h v}-\boldsymbol{E}_{\boldsymbol{g}}\right)^{r}
$$

where $\alpha$ is the absorption coefficient, $\mathrm{B}$ is a constant that depends on the material's nature., $\mathrm{h}$ is Planck constant, $v$ is the frequency of photon, $\mathrm{E}_{\mathrm{g}}$ is optical energy gap, and $\mathrm{r}$ is a constant that depends on the nature of the transition. The pulse laser deposition (PLD) technique was used, (which is located in the plasma Research Laboratory in the Physics Department at the College of Science, University of Baghdad). The experiment was conducted in a vacuum chamber under vacuum conditions $\left(2.5 \times 10^{-2}\right.$ mbar $)$. The $(\mathrm{CdO}: \mathrm{CoO})$ target was formed under $(6 \mathrm{pa})$ pressure for a duration of (10 minutes) using a hydraulic piston (type SPECAC) to 
form a disc of the target material with a $(1 \mathrm{~cm})$ and $(0.4 \mathrm{~cm})$ diameter and a thickness, respectively. In this work, glass slides were used to study the structural and morphological properties of $(\mathrm{CdO}: \mathrm{CoO})$ thin films.

$\mathrm{Nd}$ :YAG laser of wavelength $(\lambda)$, energy $(E=200,300,400,500) \mathrm{mJ}$, frequency $(f=6) \mathrm{Hz}$, and number of shots of 100 pulses. The incident Nd:YAG SHG Q-switching laser beam makes an angle of about $45^{\circ}$ degrees with the target surface. The system consists of two vacuum systems; the first vacuum is called a rotating vacuum system with two stages, as well as, a pressure and temperature gauge and a vacuum chamber, as shown in the Fig.1. The crystal structure and morphology were studied by X-ray diffraction (XRD) and atomic force microscopy (AFM). The films were also examined by ultraviolet spectroscopy (UV) to determine their optical properties.

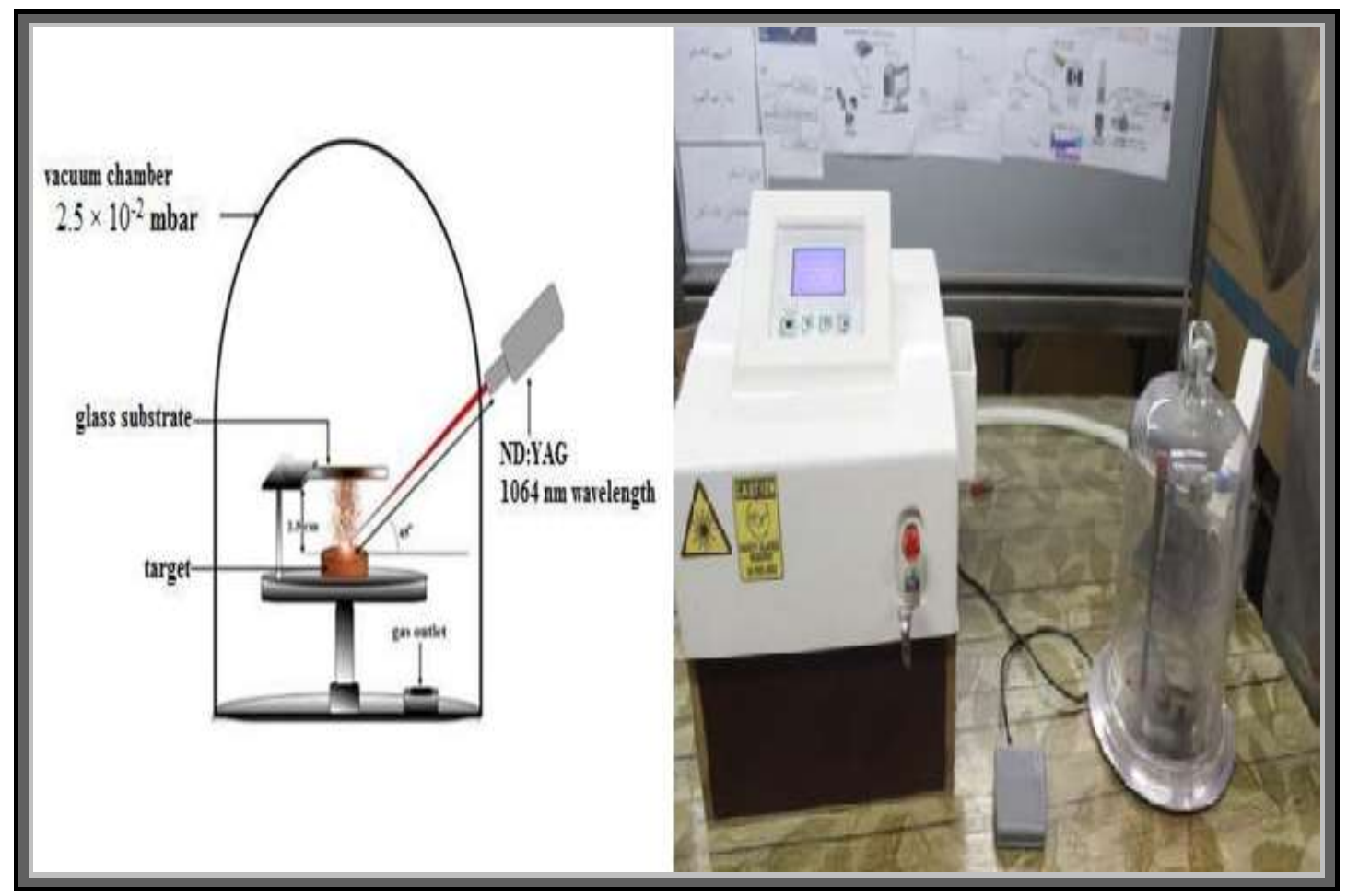

Fig. 1: Schematic diagram of pulsed laser deposition system.

\section{Results and discussion}

\section{1- X-ray diffraction examination}

X-ray diffraction technique showed that all the thin films were prepared with polycrystalline structure.

Fig. 2 shows the $(\mathrm{XRD})$ patterns of the $(\mathrm{CdO}):(\mathrm{CoO})$ composite films with different energies. These patterns are shown to have peaks centered at $2 \theta=[(33.02),(36.6)$, (38.8), (43.13), (55.02), (62.03), (66.09), (74.23), and (69.01)], belonging to Miller indices [(111), (200), (220), (311) and (222)]. The peaks at the angles (33.02),(38.8),(55.02),(66.09), and(69.01) belong to (CdO), but the peaks at the angles (36.6), (43.13), (62.03), and (74.23) belong to (CoO), These results agrees with data of the JCPDS Card (No:05-0640). It can be observed from the figure that the (CdO:CoO) thin film is of polycrystalline structure, It can be clearly seen that the film is preferentially orientated along (111) crystallographic directions. Experimental inter-plane spacing, and crystalline size were calculated by Scherer's equation. It was notice that increasing the energy caused a decrease in the intensity of the peaks, in 
addition to shifting the angles to larger $2 \theta$ values Moreover increasing the energy led to an increase in crystallization as shown in (Table 1). This is an agreement with Zhao (2002) [16].

Figs.3-5 shows the XRD results of $(\mathrm{CdO}$ and $\mathrm{CoO})$ powders and of the mix powder $(\mathrm{CdO}: \mathrm{CoO})$. The direction of the intensity spikes on the XRD plot at the different $2 \theta$ incidence angles can be related to the structure of the substance and the crystalline orientation [17]. It is observed from the Fig.3, and Fig.4 that both $\mathrm{CdO}$ and $\mathrm{CoO}$ deposited powders are of polycrystalline structure [18].

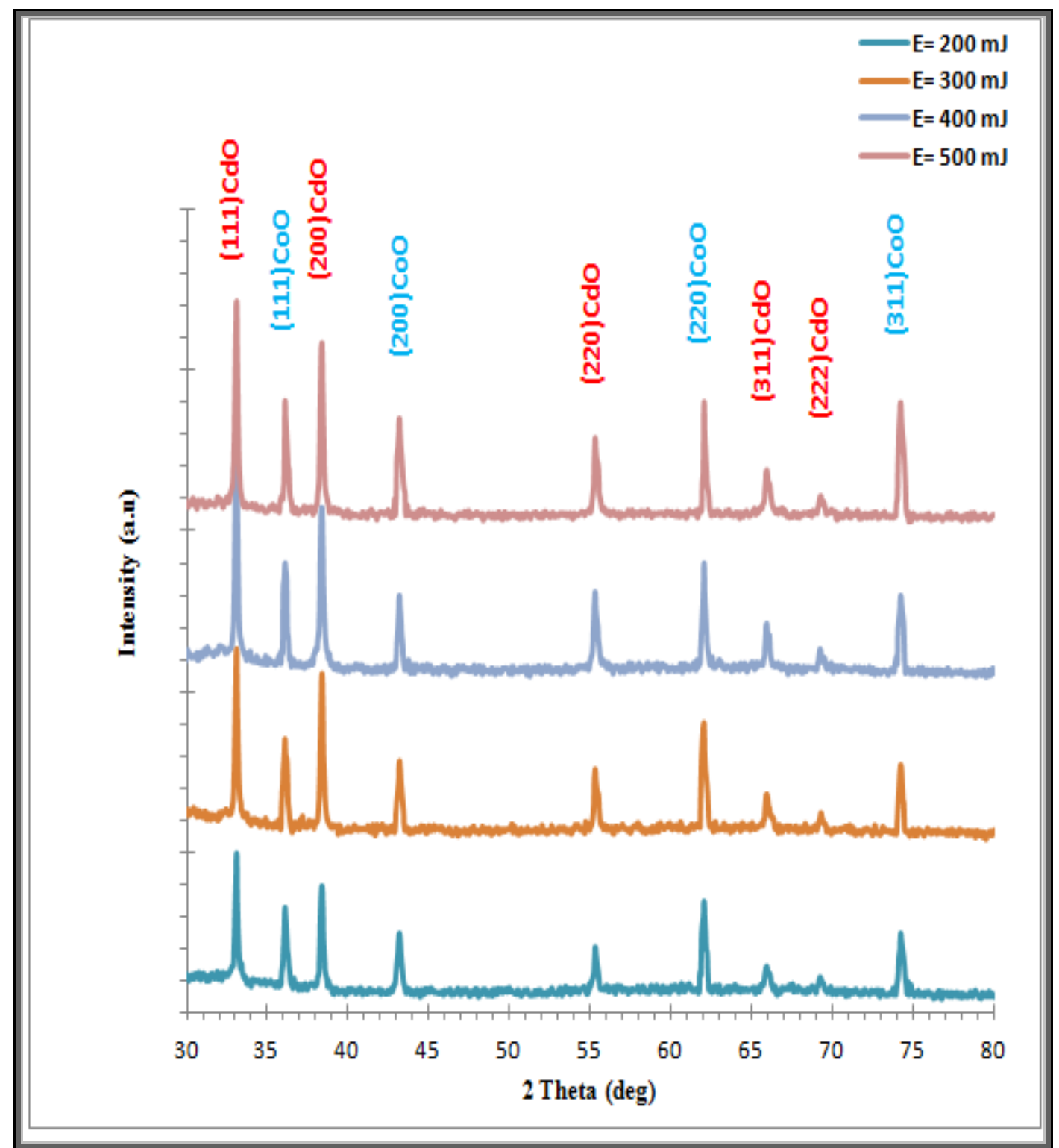

Fig. 2: XRD pattern for CdO:CoO thin films prepared with different laser energies. 
Table 1: The results of $X$-ray examination of $\mathrm{CdO}: \mathrm{CoO}$ thin films deposited with different energies.

\begin{tabular}{|c|c|c|c|c|c|c|}
\hline Laser energy & material & hkl & FWHM & $2 \theta$ & G.S (nm) & Avg G.S \\
\hline \multirow{9}{*}{$200 \mathrm{~mJ}$} & \multirow{5}{*}{$\mathrm{CdO}$} & 111 & 0.1968 & 33.0217 & 42.20493 & \multirow{5}{*}{35.27549} \\
\hline & & 200 & 0.1968 & 38.3223 & 42.83389 & \\
\hline & & 220 & 0.1968 & 55.2724 & 45.65251 & \\
\hline & & 311 & 0.3236 & 65.9182 & 29.30348 & \\
\hline & & 222 & 0.5904 & 69.3305 & 16.38263 & \\
\hline & \multirow{4}{*}{$\mathrm{CoO}$} & 111 & 0.1968 & 36.63 & 42.62119 & \multirow{4}{*}{39.29422} \\
\hline & & 200 & 0.2952 & 43.13 & 29.00128 & \\
\hline & & 220 & 0.269 & 62.03 & 34.51705 & \\
\hline & & 311 & 0.1953 & 74.13 & 51.03736 & \\
\hline \multirow{9}{*}{$300 \mathrm{~mJ}$} & \multirow{5}{*}{$\mathrm{CdO}$} & 111 & 0.1968 & 33.0217 & 42.20493 & \multirow{5}{*}{37.35725} \\
\hline & & 200 & 0.1968 & 38.3223 & 42.83389 & \\
\hline & & 220 & 0.2952 & 55.2724 & 30.43501 & \\
\hline & & 311 & 0.246 & 65.9182 & 38.54718 & \\
\hline & & 222 & 0.2952 & 69.3305 & 32.76527 & \\
\hline & \multirow{4}{*}{$\mathrm{CoO}$} & 111 & 0.1968 & 36.63 & 42.62119 & \multirow{4}{*}{40.76254} \\
\hline & & 200 & 0.264 & 43.13 & 32.42871 & \\
\hline & & 220 & 0.2512 & 62.03 & 36.96292 & \\
\hline & & 311 & 0.1953 & 74.13 & 51.03736 & \\
\hline \multirow{9}{*}{$200 \mathrm{~mJ}$} & \multirow{5}{*}{$\mathrm{CdO}$} & 111 & 0.1968 & 33.0217 & 42.20493 & \multirow{5}{*}{40.50201} \\
\hline & & 200 & 0.1968 & 38.3223 & 42.83389 & \\
\hline & & 220 & 0.246 & 55.2724 & 36.52201 & \\
\hline & & 311 & 0.1968 & 65.9182 & 48.18398 & \\
\hline & & 222 & 0.2952 & 69.3305 & 32.76527 & \\
\hline & \multirow{4}{*}{$\mathrm{CoO}$} & 111 & 0.1815 & 36.63 & 46.21405 & \multirow{4}{*}{41.82506} \\
\hline & & 200 & 0.2312 & 43.13 & 37.02932 & \\
\hline & & 220 & 0.2812 & 62.03 & 33.01951 & \\
\hline & & 311 & 0.1953 & 74.13 & 51.03736 & \\
\hline \multirow{9}{*}{$500 \mathrm{~mJ}$} & \multirow{5}{*}{$\mathrm{CdO}$} & 111 & 0.1968 & 33.0217 & 42.20493 & \multirow{5}{*}{42.72997} \\
\hline & & 200 & 0.1968 & 38.3223 & 42.83389 & \\
\hline & & 220 & 0.1568 & 55.2724 & 57.29856 & \\
\hline & & 311 & 0.246 & 65.9182 & 38.54718 & \\
\hline & & 222 & 0.2952 & 69.3305 & 32.76527 & \\
\hline & \multirow{4}{*}{$\mathrm{CoO}$} & 111 & 0.1953 & 36.63 & 42.94854 & \multirow{4}{*}{42.6588} \\
\hline & & 200 & 0.2391 & 43.13 & 35.80585 & \\
\hline & & 220 & 0.2512 & 62.03 & 36.96292 & \\
\hline & & 311 & 0.1815 & 74.13 & 54.91789 & \\
\hline
\end{tabular}




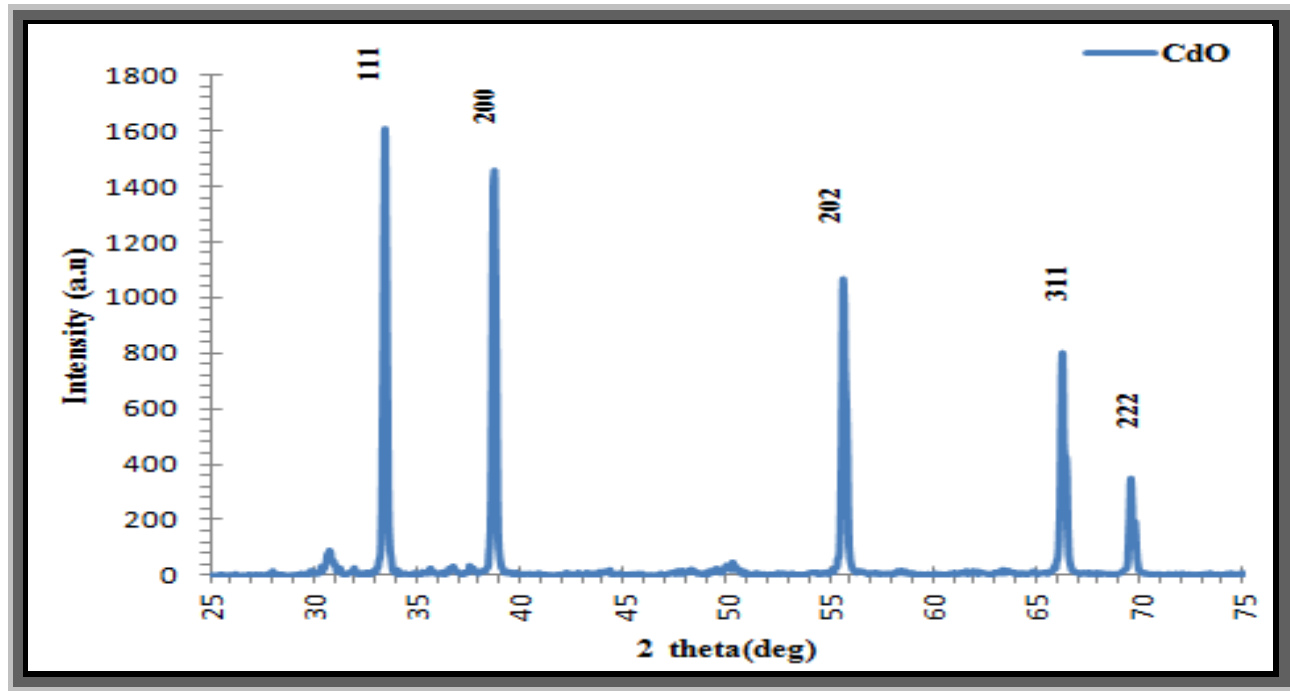

Fig. 3: Patterns of XRD for CdO powder.

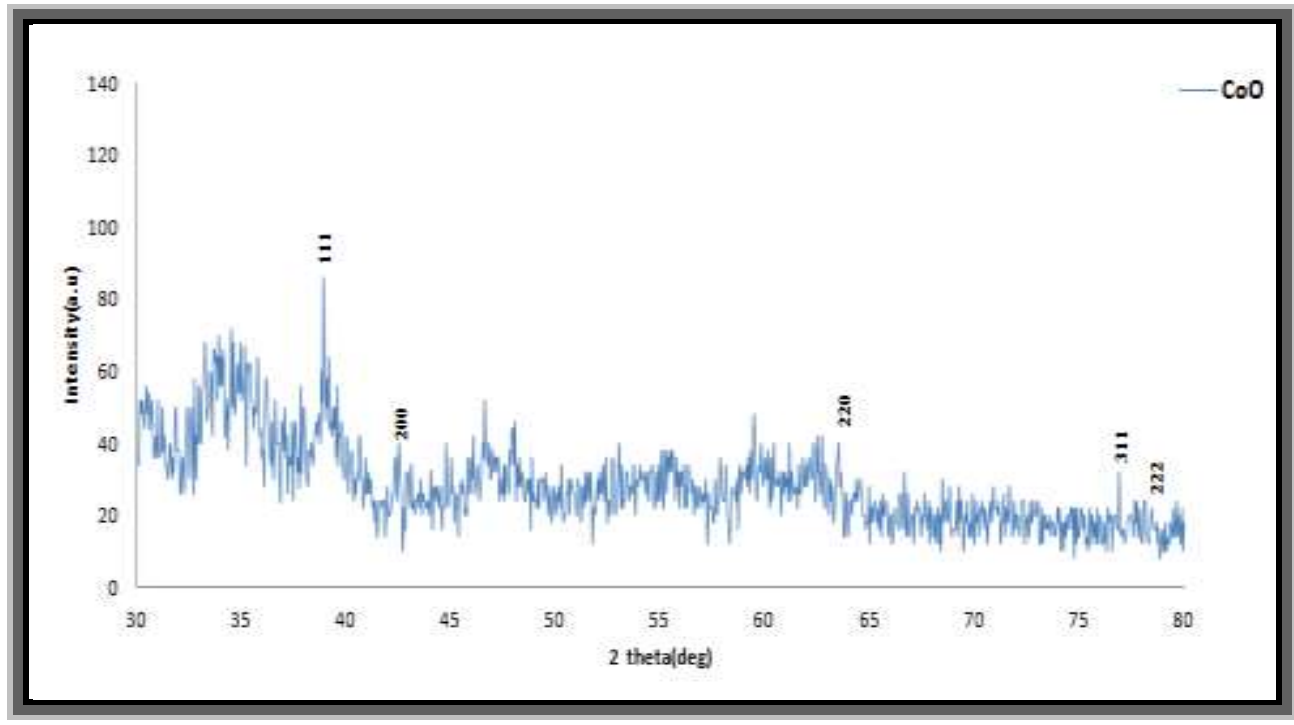

Fig. 4: Patterns of XRD for CoO powder.

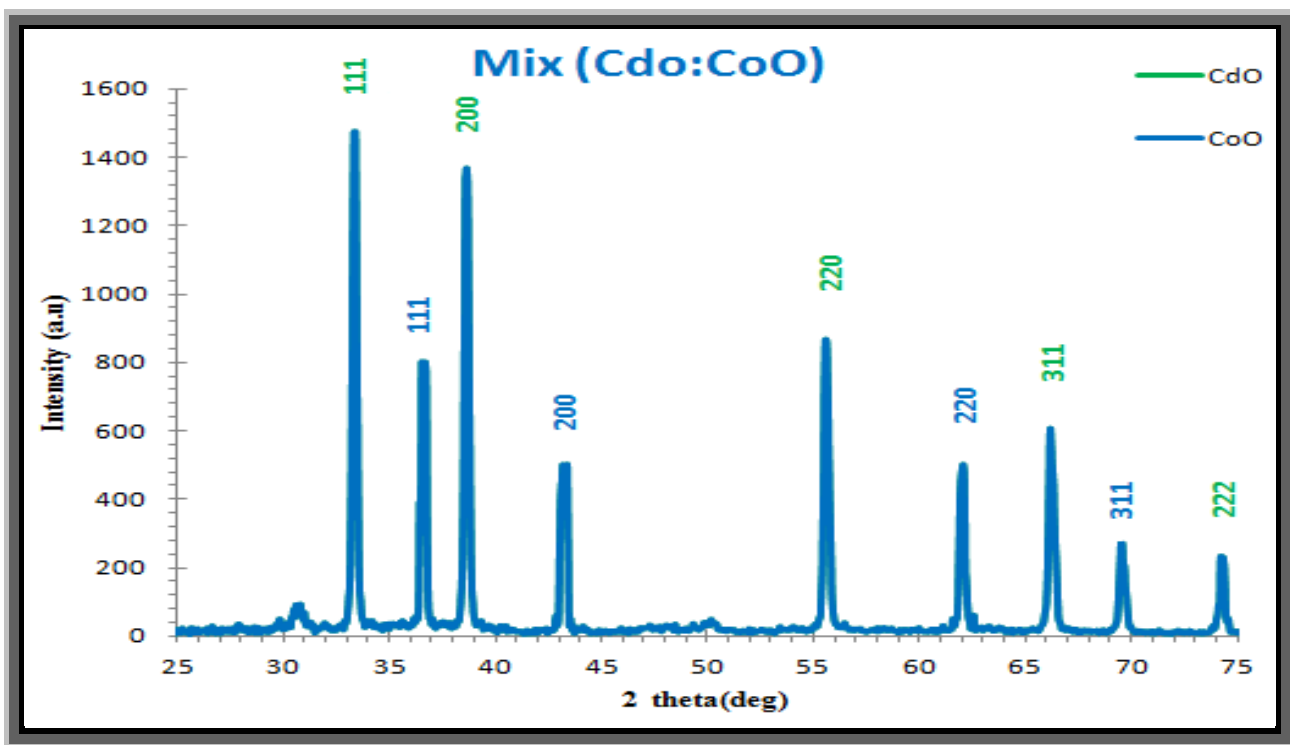

Fig. 5: Patterns of XRD for mix powder (CdO:CoO). 


\section{2- Atomic Force Microscope measurements (AFM)}

The topography of the deposit surfaces was studied with an atomic force microscope. Fig.6 shows (AFM) images of $\mathrm{CdO}: \mathrm{CoO}$ thin films with different energies.

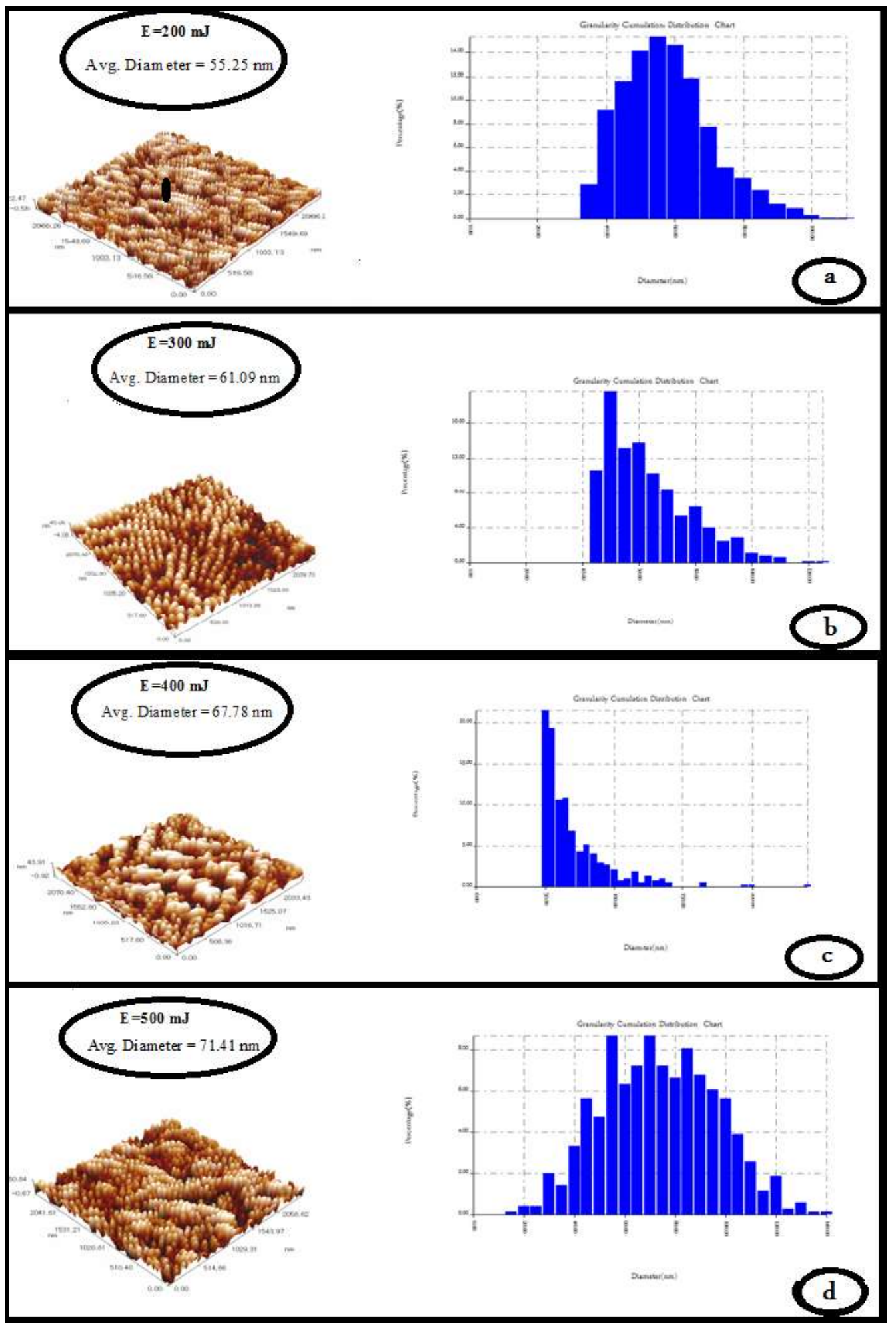

Fig.6: $\mathrm{AFM}$ images of $\mathrm{CdO}$ :CoO thin films deposited with different laser energy: (a)200mJ, (b)300mJ, (c)400mJ, and (d)500Mj. 
Table 2 shows the AFM parameters (average diameter, Root mean Square and average roughness) for $\mathrm{CdO}: \mathrm{CoO}$ thin films. The thin films were deposited on glass substrate by laser pulses.

Table 2: AFM parameters (Average Diameters, RMS and Average Roughness) for CdO:CoO thin films at different energy.

\begin{tabular}{|c|c|c|c|}
\hline laser (mJ Energy) & Avg. Diameters & Root Mean Sq.(nm) & Avg. Roughness (nm) \\
\hline 200 & 55.25 & 6.65 & 5.75 \\
\hline 300 & 61.09 & 12.50 & 10.7 \\
\hline 400 & 67.78 & 12.96 & 11.2 \\
\hline 500 & 71.41 & 14.64 & 12.7 \\
\hline
\end{tabular}

It was noticed that the granular diameter increases as the laser power energy increases This increase is due to two reasons: the first reason is that large grains are produced because of the increase of the laser energy, and the second reason is that the increase in laser energy causes small grains to combine and hence welding process occurs, producing large grains, so roughness of the surface as well as the diameter of the grain will increases [19].

\section{3- Optical properties measurements}

\section{Absorption coefficient}

The absorption coefficient was calculated from Eq. (3) [20].

$$
\alpha=\frac{2.303 A}{t}
$$

where $\mathrm{t}$ is the thickness of sample and $\mathrm{A}$ is the absorption.

Fig.7 shows the variation of absorption coefficient $(\alpha)$ with wavelength in the range of $(280-1000) \mathrm{nm}$ at thickness of sample $(\mathrm{t}=200 \mathrm{~nm})$ prepared at RT. It was observed that the absorption coefficient $(\alpha)$ increases as the laser energy of the $(\mathrm{CdO}$ : $\mathrm{CoO})$ films increases and has high value of the absorption coefficient $(\alpha)$ are larger than $10^{4} \mathrm{~cm}^{-1}$ which leads to increasing the probability of occurrence direct transition between valence band and conduction band. The absorption coefficient increases rapidly at wavelength less than cut off wavelength. The reason for the increase of the absorption coefficient with wavelength is to generate donor levels (i.e. localized states) within the forbidden energy gap and conduction band [21]. 


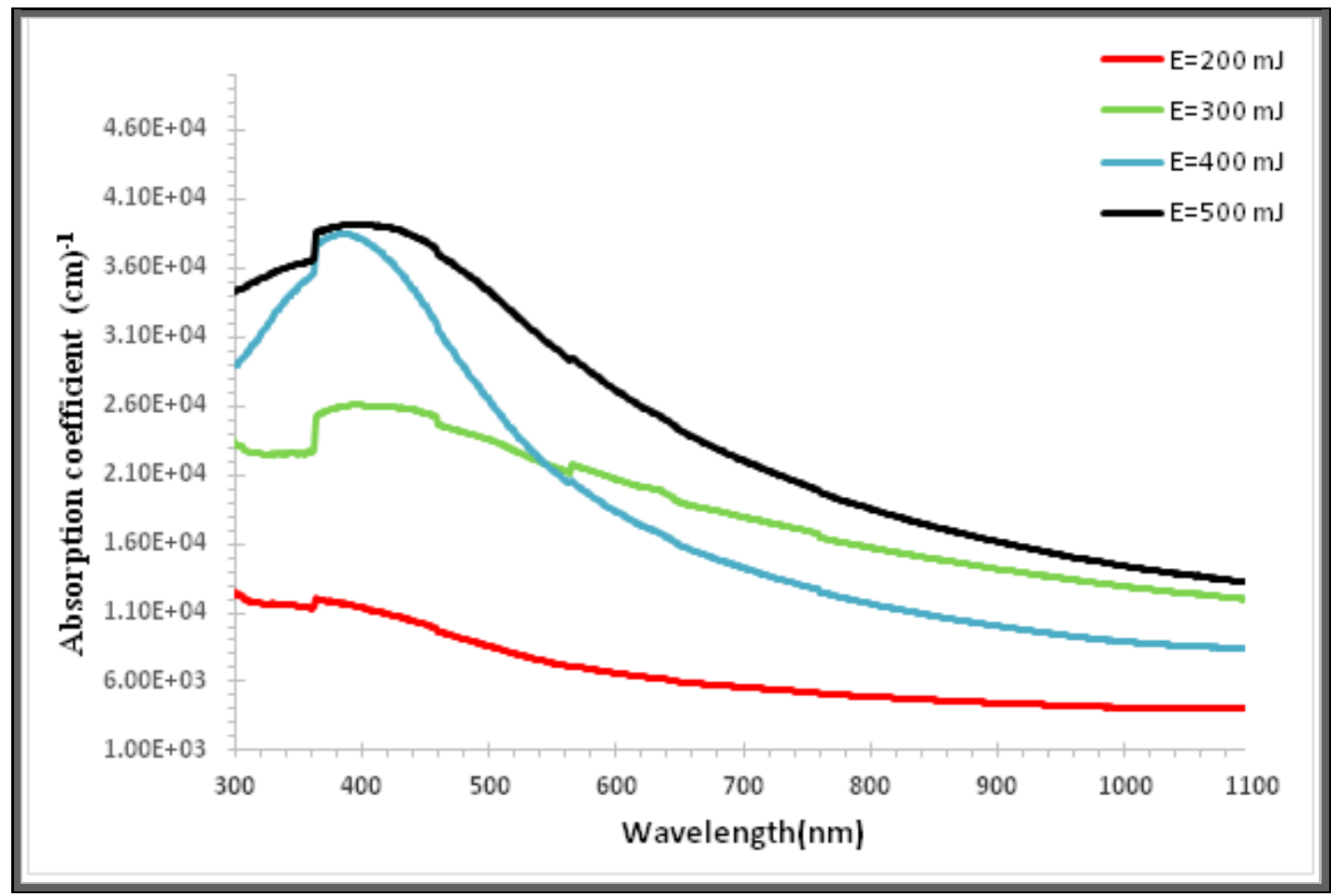

Fig.7: The variation of the absorption coefficient with wavelength of CdO:CoO films with different laser energy.

\section{Calculation of the optical energy gap (Eg)}

The optical energy gap of allowed direct electronic transitions for $\mathrm{CdO}: \mathrm{CoO}$ thin films were calculated using Tauc equation (Eq. 2) [22] as the value of $r=1 / 2$ by drawing between $(\alpha h v)^{2}$ and (hv) the energy of the falling photon and by extending the straight line of the curve to intercept the photon energy axis at the point $(\alpha h v)^{2}=0$. The optical energy gap for the allowable direct transport of $\mathrm{CdO}: \mathrm{CoO}$ films is shown in Fig.8. It is observed that the value of the energy gap decreases as the laser energy increases, resulting in the formation of localized levels near the conduction band, and so the absorption of photons is greater as the laser energy increases. (the values are shown in the Table 3). These results are found to in agreement with those of the Zheng (2011) [23]. 


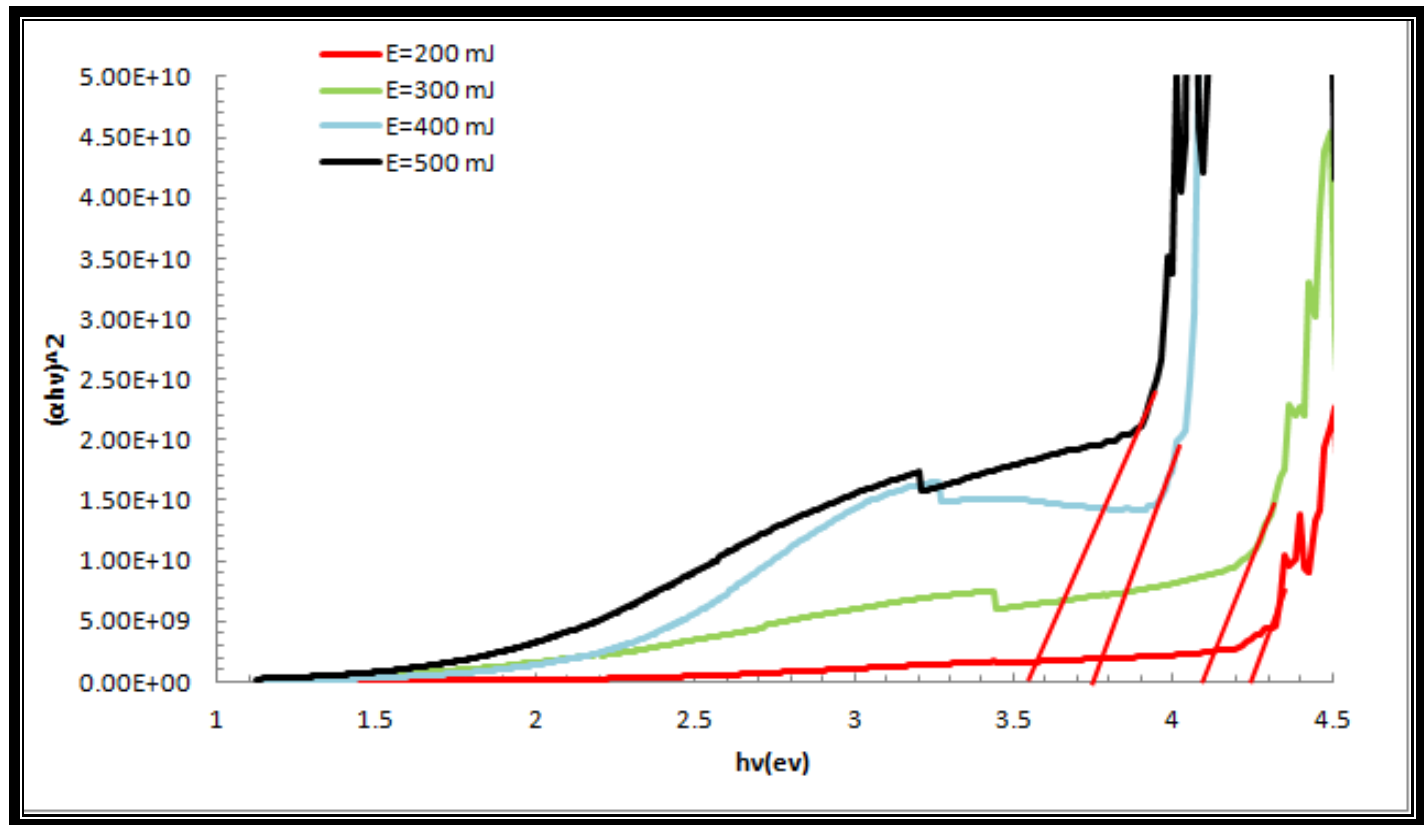

Fig. 8: The variation of $(\mathrm{ahv})^{2}$ versus photon energy (hv) for CdO:CoO films with different laser energy.

Table 3: The energy gap values for CdO:CoO thin films.

\begin{tabular}{|c|c|}
\hline Laser energy $(\mathbf{m J})$ & $\mathbf{E}_{\mathbf{g}}(\mathbf{e V})$ \\
\hline 200 & 4.25 \\
\hline 300 & 4.1 \\
\hline 400 & 3.75 \\
\hline 500 & 3.55 \\
\hline
\end{tabular}

\section{Conclusions}

Thin films of $\mathrm{CdO}: \mathrm{CoO}$ have been prepared on a glass substrate by pulsed laser deposition (PLD) technique. X-ray results showed that all thin films were polycrystalline and have a cubic structure with the dominance of direction (111). The results of AFM showed increase of the diameters average and the roughness average, in addition to the root mean square (RMS), with laser energy increase. As for the optical properties measurements, it was found that the absorption coefficient increases as the laser energy increases, whereas the energy gap, on the other hand, decreases with the laser energy increases.

\section{Acknowledgement}

The authors would like to thanks University of Baghdad, College of Science, Department of Physics, Plasma Physics Lab. for technical assistance during the research work.

\section{References}

[1] A. S. Lanje, R. S. Ningthoujam, S. J. Sharma, R. B. Pode, Indian J. Pure Appl. Phys., 49, 4 (2011) 234-238.

[2] A. J. Varkey \& A. F. Fort, Thin Solid Films, 239, 2 (1994) 211-213

[3] V.Kanniah \& A. Dhathathreyan, Journal of Chemical Sciences, 118, 2 (2006) 179184. 
[4] S. Noguchi \& M. Mizuhashi, Thin Solid Films, 77, (1-3) (1981) 99-106.

[5] Y. Azizian-Kalandaragh \& R. Shokrani-Havigh, Inorganic and Nano-Metal Chemistry, 48, 1 (2018) 1-7.

[6] C. Gutierrez-Wing, J. A. Ascencio, M. Perez-Alvarez, M. Marin-Almazo, M. Jose-Yacaman, Journal of Cluster Science, 9, 4 (1998) 529-545.

[7] J. B. Goodenough, A. Hamnett, G. Huber, F. Hullinger, M. Leiss, S.K. Ramasesha, H. Werheit, Physics of non-tetrahedrally bonded binary compounds III/Physik Der Nicht-Tetraedrisch Gebundenen Binären Verbindungen III. 1984, Springer Science \& Business Media.

[8] K.A. Aadim, B.M. Ahmed, M.A. Khalaf, Iraqi Journal of Physics (IJP), 18, 45 (2020) 1-8.

[9] K. Senthil, D. Mangalaraj, S. K. Narayandass, Applied Surface Science, 169 (2001) 476-479.

[10] L. Huang, Z. L. Wei, F. M. Zhang, X. S. Wu, Journal of Alloys and Compounds, 648 (2015) 591-594.

[11] A. I. Oliva, R. Castro-Rodriguez, O. Solıs-Canto, V. Sosa, P. Quintana, J. L. Pena, Applied Surface Science, 205, (1-4) (2003) 56-64.

[12] N. Hernandez-Como, V. Martinez-Landeros, I. Mejia, F. S. Aguirre-Tostado, C. D. Nascimento, G. D. M. Azevedo, M. A. Quevedo-Lopez, Thin Solid Films, 550 (2014) 665-668.

[13] Y. Al-Douri, M. A. Fakhri, N. Badi, C. H. Voon, Optik, 156 (2018) 886-890.

[14] M. K. Khalaf, B. T. Chiad, A. F. Ahmed, F. A. Mutlak, Int. J. Appl. Innov. Eng. Manag, 2 (2013) 178-184

[15] C.V. Reddy, R.V.S.S.N. Ravikumar, G. Srinivas, J. Shim, M. Cho, Materials Science and Engineering: B, 221 (2017) 63-72.

[16] Z. Zhao, D. L., Morel, C. S. Ferekides, Thin Solid Films, 413, (1-2) (2002) 203211.

[17] Y. Alajlani, F. Placido, H. O. Chu, R. De Bold, L. Fleming, D. Gibson, Thin Solid Films, 642 (2017) 45-50

[18] G. Salitra, G. Hodes, E. Klein, R. Tenne, Thin Solid Films, 245, (1-2) (1994) 180-185.

[19] A. F. M. Y. Haider, S. Sengupta, K. M. Abedin, A. I. Talukder, Applied Physics A, 105, 2 (2011) 487-495.

[20] E. K. Hassan, Iraqi Journal of Physics (IJP), 13, 28 (2015) 170-178.

[21] T. Asanuma, T. Matsutani, C. Liu, T. Mihara, M. Kiuchi, Journal of Applied Physics, 95, 11 (2004) 6011-6016.

[22] J. Tauc, (Ed.). “Amorphous and Liquid Semiconductors", Springer Science \& Business Media, 2012.

[23] B. J. Zheng, J. S. Lian, L. Zhao, Q. Jiang, Vacuum, 85, 9 (2011) 861-865. 